\title{
PENGARUH VARIASI DIAMETER PIPA INPUT DAN PIPA OUTPUT TERHADAP KINERJA POMPA HIDRAM
}

\author{
Budi Santoso $\mathrm{W}^{1}$, Yudi Setiawan ${ }^{2}$, Loli Tasman ${ }^{3}$ \\ ${ }^{1,2}$ Staff Pengajar Jurusan Teknik Mesin, Fakultas Teknik, Universitas Bangka Belitung \\ ${ }^{3}$ Mahasiswa Jurusan Teknik Mesin, Fakultas Teknik, Universitas Bangka Belitung \\ budi.santoso.wibowo.46@Gmail.co.id
}

\begin{abstract}
Abstrak
Provinsi Bangka Belitung merupakan salah satu provinsi yang memiliki potensi lahan pertanian yang sangat luas, dengan potensi sumber daya air melimpah disuatu daerah seringkali berlawanan dengan kondisi yang ada dimana sebagian wilayah masih terjadi kekurangan air. Seringkali adanya sumber air berada di bawah lokasi pemukiman ataupun lahan pertanian, sehingga kesulitan dalam memanfaatkannya. Penggunaan pompa listrik/diesel mempunyai konsekuensi biaya yang tidak sedikit, seperti yang dilakukan beberapa petani dengan menggunakan pompa diesel untuk mengairi ladang pertaniannya dari sungai yang ada di dekat lokasi. Salah satu teknologi yang sederhana dan murah untuk dimanfaatkan adalah dengan pemanfaatan pompa hidram. Metodelogi dalam penelitian ini adalah penggerak pompa hidram berasal dari hantaman air yang masuk kedalam pompa melalui pipa yang bergantung kepada debit aliran yang masuk kedalam pompa. Penelitian ini membahas tentang kinerja pompa hidram pada variasi diameter pipa Input dan pipa Output. Hasil dari penelitian bahwa efisiensi terbesar pompa hidram untuk debit 8 LPM adalah pada variasi diameter pipa Input 1 inchi dan pipa Output $1 \frac{1}{2}$ inchi yaitu $9,5 \%$, sedangkan efisiensi terendah pada variasi diameter pipa Input $1 \frac{1}{2}$ inchi dan pipa Output $1 \frac{1}{2}$ inchi yaitu 6,2\%. Dari hasil penelitian yang didapatkan bahwa semakin besardiameter pipa Input dan semakin kecil diameter pipa Output maka efisiensi yang dihasilkan pada pompa hidram semakin besar.
\end{abstract}

Kata Kunci: Pompa Hidram, Variasi diameter pipa Input dan Output, Efisiensi

\begin{abstract}
Bangka Belitung Province is one of the provinces that have a vast potential of agricultural land, with the potential for abundant water resources in an area that is often in contradiction with the conditions in which some regions still lack water. Often the source of water is under the location of settlements or agricultural land, so it is difficult to use it. The use of electric/diesel pumps has significant cost consequences, as some farmers do use diesel pumps to irrigate their farm fields from rivers that are nearby. One technology that is simple and inexpensive to use is the use of a hydram pump. The methodology in this study is that the hydram pump drive is derived from the impact of water entering the pump through a pipe that depends on the flow of flow entering the pump. This study discusses the performance of hydram pumps on variations in the diameter of the Input pipe and Output pipe. The results of the study that the greatest efficiency of hydram pump for discharge of 8 liters/minute is in the variation of the diameter of the Input pipe 1 inch and the Output pipe 11/2 inches is $9.5 \%$, while the lowest efficiency in the variation of the Input pipe diameter is 11/2 inches and the Output pipe 11/2 inches is 6, 2\%. The results of the study found that the larger the diameter of the Input pipe and the smaller the diameter of the Output pipe, the greater the efficiency produced at the hydram pump.
\end{abstract}

Keywords: Hydram Pump, Input and Output pipe diameter, Efficiency

\section{PENDAHULUAN}

Mietra Anggara dkk, [1] penelitin ini dilakukan tentang pengaruh variasi panjang pipa masuk (Drive Pipe) dan beban katup buang (Waste Valve) terhadap efisiensi pompa hidram. Dari penelitian ini untuk mengetahui efisiensi unjuk kerja pompa hidram dengan variasi panjang pipa masuk dan beban katup buang. Metode penelitian melalui perancangan instalasi pompa hidram dengan pengamatan pengaruh panjang pipa masuk ( 3 meter, 6 meter, 8 meter), dan pengamatan pengaruh beban katup buang $(450 \mathrm{~kg}, 830 \mathrm{~kg}, 1220 \mathrm{~kg})$ terhadap debit pompa hidram. Hasil penelitian menunjukkan bahwa efisiensi tertinggi pompa hidram adalah

41 Wibowo, Budi Santoso, dkk; Pengaruh Variasi Diameter Pipa Input Dan Pipa Output Terhadap Kinerja Pompa Hidram 
$36,19 \%$ efisiensi D'Aubuission pada berat beban 450 gram dan panjang pipa masuk 4 meter. Faktor panjang pipa masuk dan berat beban sangat berpengaruh terhadap debit pemompaan, debit buang, dan efisiensi pompa hidram.

Shodiqin [2], dalam penelitiannya yang berjudul pengaruh variasi tabung tekan terhadap efisiensi pada pompa hidram menggunakan pompa hidram dengan tinggi permukaan reservoir tetap 3 $\mathrm{m}$, panjang pipa inlet $4 \mathrm{~m}$ dengan diameter $0,0635 \mathrm{~m}$ (2,5 inchi), badan pompa berdiameter 1,5 inchi, dan pipa penghantar berdiameter 0,5 inchi dan tinggi 6 $\mathrm{m}$. Dengan variasi volume tabung tekan dengan volume $4866,35 \mathrm{~cm}^{3}, 5677,41 \mathrm{~cm}^{3}$, dan $6488,47 \mathrm{~cm}^{3}$. Hasil penelitian menunjukkan bahwa variasi volume tabung tekan berpengaruh terhadap debit dan efisiensi pompa. Pada variasi volume tabung tekan $4866,35 \mathrm{~cm}^{3}$ menghasilkan debit 0,0355 liter/detik dan efisiensi pompa hidram $10,625 \%$, pada variasi volume tabung tekan $5677,41 \mathrm{~cm}^{3}$ menghasilkan debit 0,068 liter/detik dan efisiensi pompa $24,64 \%$, dan pada variasi volume tabung tekan $6488,47 \mathrm{~cm}^{3}$ menghasilkan debit 0,072 liter/detik dan efisiensi pompa $28,32 \%$.

Aji Ageng Yuwono [3] Penelitian ini dilakukan tentang Pengaruh variasi diameter pipa inlet terhadap debit dan head pada pompa hidram. Dari penelitian pompa hidram pada pipa inlet diameter 1.5 inchi didapatkan debit dan efisiensi terbesar adalah $0,064 \%$ liter/detik dan $33,84 \%$ pada head 4 meter, sedangkan debit dan efisiensi terkecil adalah 0,018 liter/detik dan $9,69 \%$ pada head 8 meter. Pada pipa inlet diameter 2 inchi didapatkan debit dan efisiensi terbesar adalah 0.073 liter/detik dan $35,47 \%$ pada head 4 meter, sedangkan debit dan efisiensi terkecil adalah 0,022 liter/detik dan 11,49\% pada head 8 meter. Pada pipa inlet diameter 2.5 inchi didapatkan debit dan efisiensi terbesar adalah 0.082 liter/detik dan $37,88 \%$ pada head 4 meter, sedangkan debit dan efisiensi terkecil adalah 0,029 liter/detik dan $13,98 \%$ pada head 8 meter.

Sulthoni, Mohammad, [4] penelitian ini dilakukan tentang pengaruh diameter pipa inlet terhadap pemompaan pompa hidram. Dalam pengujian ini menggunakan variasi diameter 1 inchi, 1.5 inchi, 2 inchi dan panjang pipa inlet 3 meter. Pipa penghantar yang digunakan yang digunakan berdimeter o,75 inchi panjang 6 meter dan tabung udara dengan volume $4.000 \mathrm{ml}$. Pada pengujian dengan diameter dengan diameter 2 inchi didapatkan hasil paking besar yaitu 0,38 liter/detik. Pada percobaan pompa hidram ini dapat dapat disimpulkan bahwa variasi diameter berbanding lurus dengan debit pompa yang dihasilkan.

Hasan, M. Thaib. Dkk. [5] penelitian ini dilakukan tentang pengaruh panjang pipa inlet terhadap debit pompa hidram. Dalam pengujian ini menggunakan variasi panjang pipa inlet 3 meter, 4 meter, 5 meter dan diameter pipa inlet 3 inchi. Pipa penghantar yang digunakan berdiameter 0,5 inchi panjang 5 meter. Pada pengujian dengan panjang pipa inlet 5 meter didapatkan hasil paling besar yaitu 0,2583 liter/detik. Pada percobaan pompa hidram ini dapat disimpulkan bahwa semakin panjang pipa inlet maka semakin besar debit pompa yang dihasilkan.

Dari latar belakang penelitian di atas penelitian ini berfokus pada pompa hidram dengan variasi diameter pipa Input 1 inchi dan pipa Output $1 \frac{1}{2}$ inchi dengan ketinggian pipa Output 2 meter dengan tujuan untuk mengetahui kinerja dan efisiensi pompa hidram.

\section{METODE PENELITIAN}

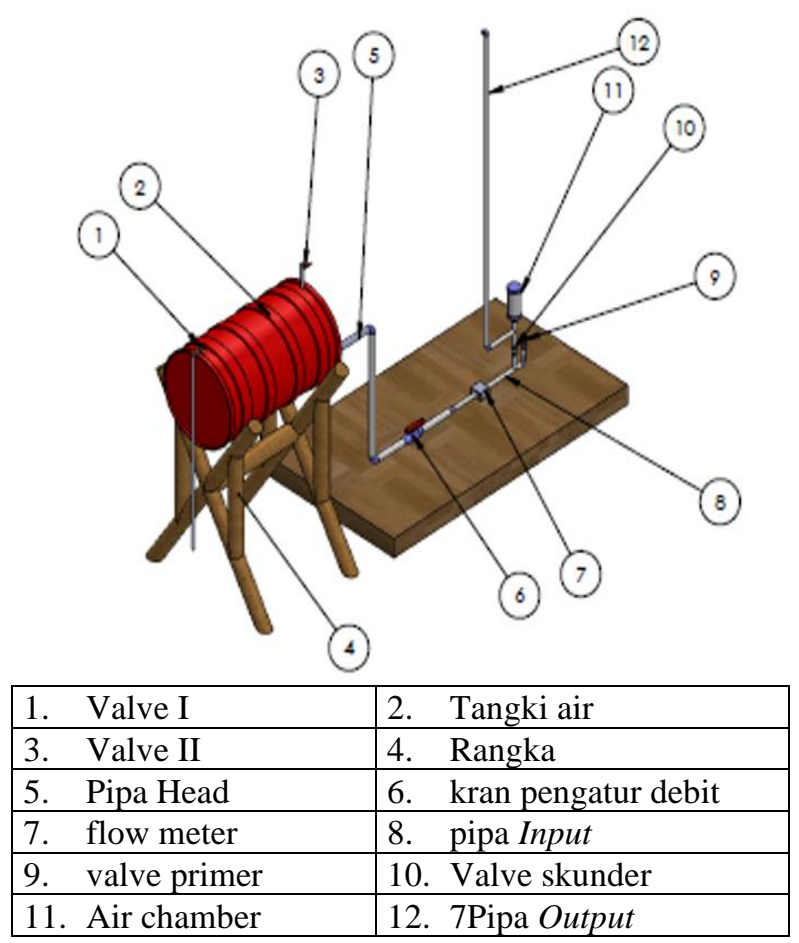

Gambar 1 Rancangan Alat Penelitian

Pengambilan data dilakukan dengan cara observasi hasil dari alat yang dibuat. pengambilan dilakukann dengan variasi pipa Input berdiameter 1 inchi dan $1 \frac{1}{2}$ inchi dengan variasi pipa Output berdiameter 1 inchi dan $1 \frac{1}{2}$ inchi dan ketinggian pipa Output dibuat konstan (h): 2 meter serta laju aliran air pada pipa Input divariasikan dengan debit laju aliran 8 LPM dan 7 LPM. Pengambilan data pada penenlitian ini adalah data debit air pada pipa Output.dengan menggunakan gelas ukur namun penelitian ini tidak menghitung tekanan air pada input dan output pompa hidram.

\section{Proses Kerja Pompa Hidram}

42 Wibowo, Budi Santoso, dkk; Pengaruh Variasi Diameter Pipa Input Dan Pipa Output Terhadap Kinerja Pompa Hidram 
Proses kerja pompa hidram pada penelitian ini antara lain sebagai berikut: Air diisi ke dalam tabung melewati stop kran pada pipa Input tabung dengan kapasitas 200 liter kemudian stop kran dibuka full supaya air mengalir ke pompa hidram. Air mengalir melalui pipa Input pompa hidram ke dalam pompa hidram menuju katup pembuangan air. Aliran air dengan kecepatan tinggi menuju katup pembuangan sehingga membuat katup buang tertutup dikarenakan katub buang terdapat pemberat menyebabkan pemberat tersebut melawan tekanan air, sehingga sebagian air keluar melalui katub buang dan sebagian air berubah arah membuat tekanan aliran air tinggi

Pada saat aliran air berubah arah dan tekanan air pada Input juga bertekanan tinggi sehingga pada saat yang bersamaan tekanan air Input pipa masuk dan tekanan air pada katup buang bertabrakan dan menyebabkan katup penghantar terbuka sehingga aliran air masuk melalui katup penghantar. Katup penghantar tertutup sehingga aliran air tidak bisa kembali lagi dan satu - satunya jalan untuk air keluar dari pipa Output sehingga aliran air keluar melalui pipa Output.

\section{HASIL DAN PEMBAHASAN}

Dari penelitian dengan debit aliran masuk dari pompa hidram 8 LPM dan 7 LPM dan dengan memvariasikan diameter pipa Input dan Output pada pompa hidram diperoleh hasil pada tabel berikut:

Tabel 1 Data Penelitian Pada Debit Input 8 LPM.

\begin{tabular}{|c|c|c|}
\hline $\begin{array}{c}\text { pipa } \\
\text { Input/Pipa } \\
\text { Output }\end{array}$ & $\begin{array}{c}\text { Debit Input } \\
\text { (LPM) }\end{array}$ & $\begin{array}{c}\text { Debit Output } \\
\text { (LPM) }\end{array}$ \\
\hline $1 \frac{1}{2} \& 1$ & 8 & 0,6 \\
\hline $1 \frac{1}{2} \& 1^{1} / 2$ & 8 & 0,5 \\
\hline $1 \& 1^{1} / 2$ & 8 & 0,76 \\
\hline $1 \& 1$ & 8 & 0,61 \\
\hline
\end{tabular}

Tabel 2 Data Penelitian Pada Debit Input 7 LPM.

\begin{tabular}{|c|c|c|}
\hline $\begin{array}{c}\text { pipa } \\
\text { Input/Pipa } \\
\text { Output }\end{array}$ & $\begin{array}{c}\text { Debit Input } \\
\text { (LPM) }\end{array}$ & $\begin{array}{c}\text { Debit Output } \\
\text { (LPM) }\end{array}$ \\
\hline $1 \frac{1}{2} \& 1$ & 7 & 0,383 \\
\hline $1 \frac{1}{2} \& 1^{1 / 2}$ & 7 & 0,3 \\
\hline $1 \& 1^{1 / 2}$ & 7 & 0,317 \\
\hline $1 \& 1$ & 7 & 0,35 \\
\hline
\end{tabular}

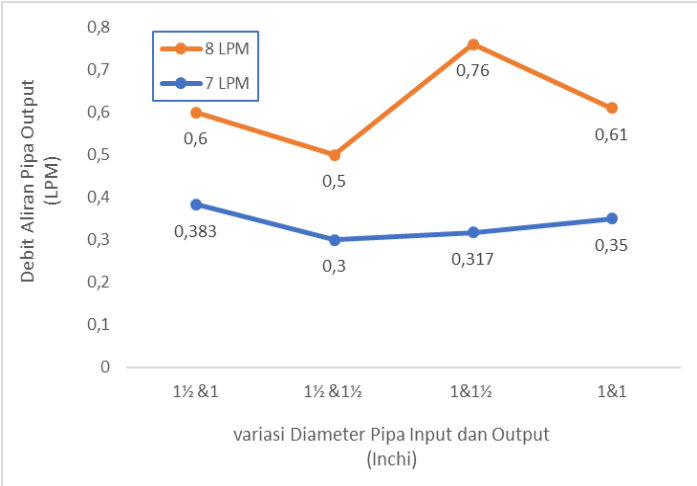

\section{Gambar 2 Grafik Hubungan Variasi Diameter Pipa Dan Debit Output Pompa Hidram}

Pada grafik di atas menunjukkan bahwa ratarata air yang keluar dari pipa Output pada pompa hidram dengan variasi pipa Input $1 \frac{1}{2}$ inchi dan pipa Output 1 inchi dengan ketinggian pipa 2 meter dan debit Input 8 LPM debit Output air yang dihasilkan dari pipa Output yaitu 0,6 LPM. Sedangkan debit Input 7 LPM debit Output air yang yang dihasilkan yaitu 0,383 LPM.

Pada variasi pipa Input $1 \frac{1 / 2}{2}$ dan pipa Output $1 \frac{1}{2}$ dengan ketinggian pipa 2 meter dan debit air 8 LPM maka air yang dihasilkan dari pipa Output yaitu 0,5 LPM. Sedangkan debit Input 7 LPM air yang dihasilkan dari pipa Output yaitu 0,3 LPM.

Pada variasi pipa Input 1 inchi dan pipa Output $1 \frac{1 / 2}{2}$ inchi dengan ketinggian pipa 2 meter dan debit Input 8 LPM maka air yang dihasilkan dari pipa Output yaitu 0,763 LPM. Sedangkan debit Input 7 LPM air yang dihasilkan dari pipa Output yaitu 0,317 LPM.

Pada variasi pipa Input 1 inchi dan pipa Output 1 inchi dengan ketinggian pipa 2 meter dan debit Input 8 LPM maka air yang dihasilkan dari pipa Output yaitu 0,617 LPM. Sedangkan debit Input 7 LPM air yang dihasilkan dari pipa Output yaitu 0,35 LPM. Pada grafik perbandingan di atas semakin besar diameter pipa Input dan semakin kecil diameter pipa Output maka debit Output air yang dihasilkan pompa hidram akan semakin besar

\section{Efisensi Pompa Hidram}

Perhitungan efisiensi rata - rata dari pompa hidram dapat dihitung dengan menggunakan rumus di bawah ini :

Rumus :

$$
\eta=\frac{\text { output }}{\text { Input }} \times 100 \%
$$

Dimana :

$$
\begin{array}{ll}
\boldsymbol{\eta} & =\text { Efisiensi pompa hidram } \\
\text { Output } & =\text { Debit air yang keluar (LPM) }
\end{array}
$$

43 Wibowo, Budi Santoso, dkk; Pengaruh Variasi Diameter Pipa Input Dan Pipa Output Terhadap Kinerja Pompa Hidram 
Input = Debit air yang masuk (LPM)

Tabel 3 Efisiensi Kinerja Pompa Hidram.

\begin{tabular}{|c|c|c|c|}
\hline No & $\begin{array}{l}\text { Debit } \\
\text { Input } \\
\text { (LPM) }\end{array}$ & $\begin{array}{l}\text { Variasi Pipa Input } \\
\text { dan pipa Output }\end{array}$ & $\begin{array}{l}\text { Efisiensi } \\
\text { pompa } \\
\text { hidram } \\
(\%)\end{array}$ \\
\hline \multirow{4}{*}{1.} & \multirow{4}{*}{8} & $\begin{array}{l}1 \frac{1}{2} \text { inchi dan } 1 \\
\text { inchi }\end{array}$ & $7,5 \%$ \\
\hline & & $\begin{array}{l}1 \frac{1}{2} \text { inchi dan } 1 \frac{1}{2} \\
\text { inchi }\end{array}$ & $6,2 \%$ \\
\hline & & $\begin{array}{l}1 \text { inchi dan } 1 \frac{1}{2} \\
\text { inchi }\end{array}$ & $9,5 \%$ \\
\hline & & 1 inchi dan 1 inchi & $7,7 \%$ \\
\hline \multirow{4}{*}{2.} & \multirow{4}{*}{7} & $\begin{array}{l}1 \frac{1}{2} \text { inchi dan } 1 \\
\text { inchi }\end{array}$ & $5,4 \%$ \\
\hline & & $\begin{array}{l}11 / 2 \text { inchi dan } 1 \frac{1}{2} \\
\text { inchi }\end{array}$ & $4,2 \%$ \\
\hline & & $\begin{array}{l}1 \text { inchi dan } 1 \frac{1}{2} \\
\text { inchi }\end{array}$ & $4,5 \%$ \\
\hline & & 1 inchi dan 1 inchi & $5 \%$ \\
\hline
\end{tabular}

Nilai efisiensi tertinggi untuk debit Input 8 LPM dengan variasi diameter pipa Input 1 inchi dan pipa Output $1 \frac{1}{2}$ inchi yaitu $9,5 \%$, sedangkan untuk debit Input 7 LPM efisiensi tertingginya dengan variasi diameter pipa Input $1 \frac{1}{2}$ inchi dan pipa Output 1 inchi yaitu 5,4\% dan efisiensi terendah pada pompa hidram yaitu pada debit Input 8 LPM dengan variasi diameter pipa Input $1 \frac{1}{2}$ inchi dan pipa Output $1 \frac{1}{2}$ inchi yaitu $6,2 \%$, sedangkan untuk debit Input 7 LPM efisiensi terendah dengan variasi diameter pipa Input $1 \frac{1 / 2}{2}$ inchi dan pipa Output $1 \frac{1 / 2}{2}$ inchi $4,2 \%$.

\section{KESIMPULAN}

Debit aliran pada pipa Output yang dihasilkan pompa hidram pada ketinggian pipa $2 \mathrm{~m}$ terbesar yaitu 0,763 LPM dengan variasi diameter pipa Input 1 inchi dan pipa Output 11/2 inchi dengan debit Input 8 LPM. sedangkan debit aliran Output terendah yaitu 0,3 LPM pada variasi diameter pipa Input $1 \frac{1}{2}$ inchi dan pipa Output $1 \frac{1}{2}$ dengan debit Input 7 LPM.

Efisiensi pompa hidram terbesar adalah pada variasi diameter pipa Input 1 inchi dan pipa Output $1 \frac{1}{2}$ inchi dengan debit Input 8 LPM yaitu 9,5\%, sedangkan untuk efisiensi terendah terjadi pada debit Input 7 LPM pada variasi diameter pipa Input $1 \frac{1}{2}$ inchi dan pipa Output 11/2 inchi yaitu 4,2\%.

\section{DAFTAR PUSTAKA}

[1] Mietra Anggara, dkk.2013. Pengaruh Variasi Panjang Pipa Masuk (Drive Pipe) dan Beban Katup Buang (Waste Valve) Terhadap Efisiensi Pompa Hidram. Volume 5. No 2

[2] Shodiqin. 2015. Variasi Volume Tabung Tekan: Terhadap Kinerja Pompa Hidram. Jurusan Teknik Mesin Universitas Muhammadiyah Surakarta

[3] Ageng Yuwono, Aji (2015) Pengaruh Variasi Diameter Pipa Inlet Terhadap Debit Dan Head Pada Pompa Hidram. Diploma Thesis, Universitas Muhammadiyah Surakarta.

[4] Sulthoni, M. (2011). Pengaruh Diameter Pipa Inlet Terhadap Debit Pemompaan Pompa Hidram.Jurnal Semantic Scholar

[5] Hasan, M. Thaib. Dkk. 2014. Pengaruh Panjang Pipa Keluaran Terhadap Kinerja Pompa Hidraulic Ram Pump (Hydram). Jurnal Ilmiah Jurutera Volume 01 No. 02 (11.2014) 001-005 